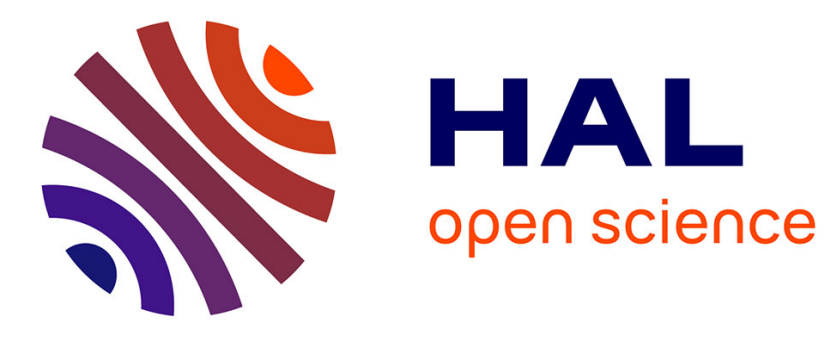

\title{
Driving after concussion: Is it safe to drive after symptoms resolve?
}

Julianne Schmidt, Nicole L Hoffman, Maud Ranchet, Stephen Miller, Phillip

Tomporowski, Abiodun Emmanuel Akinwuntan, Hannes Devos

\section{To cite this version:}

Julianne Schmidt, Nicole L Hoffman, Maud Ranchet, Stephen Miller, Phillip Tomporowski, et al.. Driving after concussion: Is it safe to drive after symptoms resolve?. Journal of Neurotrauma, 2016, 34 (8), pp.1571-1578. 10.1089/neu.2016.4668 . hal-01425252v3

HAL Id: hal-01425252

https://hal.science/hal-01425252v3

Submitted on 21 Jun 2017

HAL is a multi-disciplinary open access archive for the deposit and dissemination of scientific research documents, whether they are published or not. The documents may come from teaching and research institutions in France or abroad, or from public or private research centers.
L'archive ouverte pluridisciplinaire HAL, est destinée au dépôt et à la diffusion de documents scientifiques de niveau recherche, publiés ou non, émanant des établissements d'enseignement et de recherche français ou étrangers, des laboratoires publics ou privés. 


\section{Title: Driving after concussion: Is it safe to drive after symptoms resolve?}

Running Title: Driving after concussion

\section{Authors:}

Corresponding Author: Julianne D. Schmidt, PhD, ATC

Affiliation: Department of Kinesiology, University of Georgia, Athens, GA

Email: schmidtj@uga.edu

Address: 330 River Rd, Athens GA 30602

Office: (706)542-4388

Fax: (706)542-3148

Nicole L. Hoffman, MS, ATC

Affiliation: Department of Kinesiology, University of Georgia, Athens, GA

Email:nhoffman25@uga.edu

Address: 330 River Rd, Athens GA 30602

Office: (706)542-3273

Fax: (706)542-3148

\section{Maud Ranchet, PhD}

Affiliation: Department of Physical Therapy, College of Allied Health Sciences, Augusta University, Augusta, GA \& Laboratory Ergonomics and Cognitive Sciences applied to Transport, Transport Health Safety Department, IFSTTAR, Lyon, France

\section{Email: maud.ranchet@ifsttar.fr}

Address: 25, avenue François Mitterrand - 69675 Bron cedex

Office: +33 (0)4 72142599 
Fax: None

L. Stephen Miller, PhD

Affiliation: Department of Psychology, University of Georgia, Athens, GA

Email: Ismiller@uga.edu

Address: 125 Baldwin Street, Athens, GA 30602

Office: (706) 542-1173

Fax: (706)542-8048

Phillip D. Tomporowski, PhD

Affiliation: Department of Kinesiology, University of Georgia, Athens, GA

Email:ptomporo@uga.edu

Address: 330 River Rd, Athens GA 30602

Office: (706)542-4183

Fax: (706)542-3148

Abiodun E. Akinwuntan, $\mathrm{PhD}, \mathrm{MPH}, \mathrm{MBA}$

Affiliation: University of Kansas Medical Center, Kansas City, KS

Email: aakinwuntan@kumc.edu

Address: 3901 Rainbow Boulevard, Kansas City, KS 66160

Office: (913)588-5254

Fax:

Hannes Devos, PhD, DRS

Affiliation: Department of Physical Therapy, College of Allied Health Sciences, Augusta University, Augusta, GA \& University of Kansas Medical Center, Kansas City, KS 
Email: hdevos@kumc.edu

Address: 3901 Rainbow Boulevard, Kansas City, KS 66160

Office: (706)721-2743

Fax: (706)721-3209 


\section{Abstract}

Post-concussion impairments may result in unsafe driving performance, but little research is available to guide consensus on when concussed individuals should return to driving. The purpose of this study was to compare driving performance between individuals with and without a concussion and to explore relationships between neuropsychological and driving performance. Fourteen participants with concussion (Age:20.2 $\pm 0.9 y 0$ ) and 14 non-concussed age and driving experience matched controls (Age:20.4 \pm 1.1 yo) completed a graded symptom checklist, a brief neuropsychological exam, and a $20.5 \mathrm{~km}$ driving simulation task. Participants with a concussion completed driving simulation within 48 hours of becoming asymptomatic (15.9 \pm 9.0 days post-concussion). One-way ANOVAs were used to compare total number of crashes, tickets, lane excursions; as well as standard deviation of lateral position (SDLP), and standard deviation of speed. Pearson's correlations were conducted to explore the relationship between the neuropsychological and driving performance separately by group $(\alpha=0.05)$. Participants with a concussion committed more frequent lane excursions (concussed:10.9 \pm 4.5 ; controls:7.4 $\pm 2.4 ; p=0.017$ ) and exhibited greater SDLP compared to controls during the first (concussed:45.7 $\pm 21.3 \mathrm{~cm}$, controls:27.4 $\pm 6.1 \mathrm{~cm} ; \mathrm{p}=0.030$ ) and final curve (concussed:39.6 $\pm 24.4 \mathrm{~cm}$; controls:33.5 $\pm 21.3 \mathrm{~cm} ; \mathrm{p}=0.036)$. Poorer performance on symbol digit modalities $(r=-0.54)$, Rey Osterrieth Complex Figure $(r=-0.53)$, verbal memory $(r=-0.77)$, and motor speed $(r=-0.54)$ were correlated with more frequent lane excursions among the concussed group, but not the control group. Despite being 
asymptomatic, concussed participants exhibited poorer vehicle control, especially when navigating curves. Driving impairments may persist beyond when individuals with a concussion have returned to driving. Our study provides preliminary guidance regarding which neuropsychological functions may best indicate driving impairment following concussion.

Keywords: Mild traumatic brain injury, post-concussion, driving safety 


\section{Introduction}

Concussion, also known as mild traumatic brain injury, is a major public health concern in the United States. ${ }^{1}$ Relatively little research has examined whether individuals recovering from a concussion are safe to drive, despite common neuropsychological impairments in areas such as reaction time, executive function, and attention persisting after symptoms resolve..$^{2-4}$ These cognitive impairments may impede the ability to drive following concussion. However, no formal guidelines exist in determining a concussed individual's readiness to return to driving.

Concussion-related symptoms typically resolve within 7 days following injury. ${ }^{3,5}$ However, $26 \%$ of individuals with a concussion continue to experience neuropsychological deficits once asymptomatic (following symptom resolution). ${ }^{5}$ Because symptom resolution causes individuals with a concussion to perceive that they have fully recovered from their injury, they are often unaware of their deficits and may feel that they are ready to return to driving. It seems likely that neuropsychological deficits would negatively affect an individual's ability to drive. However, there is very little research available to guide consensus on when individuals that sustain a concussion should return to driving. In fact, consensus statements regarding concussion address return to sport and return to school, but do not address return to driving. ${ }^{6}$ Driving in an impaired state carries very serious consequences that may affect both the individual with a concussion and others on the road. 
Driving is a highly complicated activity that requires the timely interaction of visual, motor, and cognitive skills to adequately respond to a dynamic, constantly changing environment. ${ }^{7}$ Driving impairments are well documented in populations with less subtle neurological disorders such as moderate and severe traumatic brain injury, Alzheimer's disease, Parkinson's disease, and various other neurological conditions, ${ }^{8-13}$ but little is known about how mild neurological impairments such as concussion influence driving performance. Although it makes intuitive sense to restrict or reduce driving following concussion, only $48 \%$ of individuals intend to reduce their driving at any point after sustaining a concussion. ${ }^{14}$ Patients were assessed within 24 hours following concussion are slower to identify hazards within their field of view while driving ${ }^{15}$. Individuals with a history of concussion have greater risk of collision ${ }^{16}$, but do not differ in hazard detection ${ }^{17}$. Combined these studies suggest that driving performance is impaired following concussion, but driving impairments likely eventually resolve. However, it seems likely that a concussed individual return to driving before or once they perceive that they have recovered. ${ }^{15}$

The primary purpose of this study was to compare driving performance between individuals with a concussion and non-concussed matched controls. Driving performance was assessed within 48 hours following symptom resolution because this is the most likely time at which a concussed individual would return to driving. We hypothesized that individuals who have sustained a concussion would perform worse on a driving test compared to non-concussed matched controls. We also aimed to determine if neuropsychological performances 
correlated with simulated driving performances among individuals with a concussion and non-concussed matched controls.

\section{Methods}

Fourteen individuals with a concussion between 18 and 25 years old and 14 controls individually matched for age, gender, and years of driving experience completed an institutional review board approved informed consent, a demographic form, graded symptom checklist, driving simulation, and neuropsychological exam. All participants were of driving age and had not sustained more than 3 previous self-reported concussions. ${ }^{18}$ All but two participants possessed a class $\mathrm{C}$ driver's license. One concussed participant possessed a class B commercial driver's license, so we recruited a matched control with the same license type and occupation (bus driver). Any participant that reported a history of other major neurological disorders/injury, current use of any medications that evokes drowsiness, or heavy use of alcohol/drugs was excluded. Participants in the concussed group were diagnosed with a concussion by a health care professional using the criteria outlined by the 2013 Consensus Statement on Concussion in Sport ${ }^{6}$ and completed testing within 48 hours of experiencing symptom resolution. Concussed participants were recruited during their initial evaluation provided by our clinical research laboratory and included both Division I collegiate athletes and college students. The concussed group consisted of 2 collegiate athletes referred by the athletic association and 13 college students referred by the University Health Center. Participants in the nonconcussed group were required to have no history of a concussion within the 
past 24 months. Control participants were recruited using flyers posted oncampus. All participants were provided with a small monetary compensation for their time.

\section{Graded Symptom Checklist}

The graded symptom checklist is a 7-point Likert scale grading system that was used to confirm that all participants had experienced symptom resolution prior to data collection. ${ }^{19} \mathrm{We}$ administered the graded symptom checklist to both concussed and non-concussed participants to assess 18 concussion-related symptoms that they experience on a regular basis (defined as 3 or more times per week) prior to the assessment. ${ }^{20}$ An investigator (JDS, NLH) read the list of symptoms and the participant verbally graded each symptom on a scale of 0 to 6 , where 1 to 2 means that the symptoms is mild, 3 to 4 means the symptom is moderate, 5 to 6 means the symptom is severe, and 0 means that they do not experience the symptom more than three times per week. We then administered the graded symptom checklist again to determine how each participant was currently feeling (defined as within the past 48 hours). We calculated the total symptom score on a regular basis and at the assessment time by summing the responses across all of the symptoms (max=108) (Table 2). All participants were deemed asymptomatic based on our criteria that their total symptom score for how they were currently feeling was less than 10 points greater than their total symptom score for how they felt on a regular basis. ${ }^{19}$

\section{Driving Performance}


Performance during driving a desktop simulator that was powered on STISIM drive ${ }^{\circledR}$ software, version 3 (STI Inc, Hawthorne, CA) was used a measure of driving ability. Images from the simulator were projected on three 25 " screens (145 degrees of horizontal field of view). Participants used a Logitech ${ }^{\circledR}$ steering wheel and two pedals to navigate through the scenarios (Figure 1). All participants first completed a 5-minute familiarization program to get acquainted with the driving simulator scenarios and tasks, and to reduce simulator discomfort. Participants then completed a $20.5 \mathrm{~km}$ driving simulation task involving daily-life traffic in urban, suburban, and rural areas (Figure 2). This evaluation scenario comprised driving on straight and curvy (3 curves: left/smooth, right/smooth, left/sharp), two-lane and four-lane roads, overtaking, speed adaptations, and stopping at crosswalks and red lights. Within the $20.5 \mathrm{~km}$ drive, events such as a child suddenly crossing the street, a car suddenly pulling out, or oncoming vehicles drifting in the driver's lane, were used to evaluate hazard perception and emergency brake responses.

Computer-generated outcome variables for the whole simulation drive included total number of crashes, tickets, and lane excursions (center line crossings and road edge excursions). For each segment of the drive, we also collected sensitive data of vehicle control and risk of crashes, such as standard deviation of lateral position (SDLP) and standard deviation of speed. ${ }^{21}$ SDLP is a measure of lateral vehicle control and reflects the amount of weaving of the car. Standard deviation of speed is a measure of longitudinal vehicle control and refers to the variability in speed. These variables were collected at $60 \mathrm{~Hz}$. We 
administered the driving simulator sickness questionnaire ${ }^{22}$ following the driving simulation familiarization and evaluation scenarios to monitor symptoms of the simulator adaptation syndrome, but no participants experienced discomfort during the driving simulation.

\section{Neuropsychological Assessment}

Each participant completed a brief neuropsychological evaluation (counterbalanced with Driving Simulator Assessment) administered by an experienced researcher (JDS, NLH). These assessments were chosen because they are widely used and representative of a comprehensive battery of neuropsychological functions. Assessment order was randomized. Trails Making Test ${ }^{17}$ : Participants completed the Trail Making Tests A \& B to assess visual tracking and task switching. In Trails A, participants were instructed to connect 25 circles in ascending order. Trails B consists of circles that include both numbers $(1-13)$ and letters $(A-L)$. The participant drew a line to connect the circles in an ascending, but alternating pattern (i.e.1-A-2-B-3-C, etc.). Investigators recorded the total time in seconds to complete Trails A and B.

Symbol Digit Modalities Test ${ }^{17}$ : Participants completed the symbol digit modalities test to evaluate attention, working memory, and psychomotor speed. The participant viewed a reference key that consists of a grid of 9 symbols each numbered 1 through 9 . A blank grid was presented under the key where the symbols were present, but the corresponding numbers were 
not. The participant had 90 seconds to fill in as many numbers as possible. The investigator recorded the number of correct responses. Rey Osterrieth Complex Figure-ROCF copy and recall18: Participants completed the ROCF to evaluate visuo-spatial ability and visuo-constructive skills. Participants were asked to reproduce the ROCF to the best of their ability. The investigator recorded the time to complete the copy of the ROCF. Five minutes after completion of the copy test the participants were asked to reproduce the ROCF from memory. The investigators scored for the accuracy and placement of 18 specific design elements.

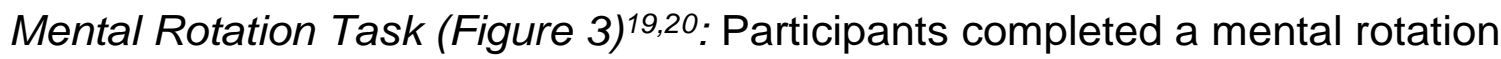
experiment using the online psychology laboratory (Cognition Laboratory Experiments) via Hanover College..$^{23}$ During the mental rotation test, participants compared two three-dimensional objects to determine whether they are the same image or if they are mirror images. The test had pairs of images each rotated either $0^{\circ}, 60^{\circ}, 120^{\circ}$, or $180^{\circ}$. Some pairs were the same image rotated, and others were mirrored. Participants were shown 70 same and mirrored pairs and were judged on how accurately and rapidly they distinguished between pairs.

Computerized Neuropsychological Evaluation ${ }^{24}$ : Participants completed CNS Vital Signs which includes the following subtests: verbal memory, visual memory, finger tapping, symbol digit coding, Stroop, shifting attention, and continuous performance. Domains examined included verbal memory, visual memory, psychomotor speed, reaction time, complex attention, cognitive flexibility, 
processing speed, executive function, simple attention, and motor speed. Neuropsychological outcome measures that exceeded 1.5 times the interquartile range were deemed outliers and excluded from corresponding analyses. ${ }^{25}$ Statistical Analyses

To address our primary purpose, one-way ANOVAs were used to compare differences between groups in total symptom scores, neuropsychological performance, and simulated driving performance after checking the normal distribution of data by Shapiro Wilk test $(\alpha=0.05)$. Dependent variables included the following outcome measures: total symptom score, Trails A/B time, symbol digit modalities number correct responses, ROCF time and accuracy, mental rotation time and accuracy, verbal memory, visual memory, psychomotor speed, reaction time, complex attention, cognitive flexibility, processing speed, executive function, simple attention, motor speed; and the following driving performance measures: total number of crashes, tickets, and lane excursions. We also compared standard deviation of lateral position (SDLP) and standard deviation of speed throughout simulation subsections. Pearson's correlations were conducted to explore the relationship between the neuropsychological and driving performance variables separately for the concussed and control group ( $\alpha=0.05$ ). Correlations were considered to be weak below 0.10 , moderate between 0.10 and 0.49 , and strong between 0.50 and $1.00 .^{26}$

\section{Results}


Descriptive and statistical results for demographic and driving performance variable comparisons are presented in Table 1. Descriptive and statistical results for graded symptom checklist and neuropsychological assessment variable comparisons are presented in Table 2. Concussed and control participants did not differ on any demographic variable total symptom scores, or any neuropsychological assessment $(p>0.05)$.

Concussed participants committed more frequent lane excursions compared to controls (concussed: $10.9 \pm 4.5$, controls: $7.4 \pm 2.4 ; p=0.017$ ), but did not differ in total crashes or tickets (Table 1). Further analyses revealed that individuals with a concussion committed more road edge excursions, but not centerline crossings, compared to controls. Concussed participants exhibited greater SDLP compared to controls during the first smooth left (concussed: $0.46 \pm 0.21 \mathrm{~m}$, controls: $0.27 \pm 0.06 \mathrm{~m} ; \mathrm{p}=0.030$ ) and final sharp left curves (concussed: $0.40 \pm 0.24 \mathrm{~m}$; controls: $0.34 \pm 0.21 \mathrm{~m} ; \mathrm{p}=0.036$ ), but not the second smooth right curve. Concussed participants also exhibited greater standard deviation of speed maintenance in the final left curve of the simulation compared to controls (concussed: $9.00 \pm 2.30 \mathrm{~km} / \mathrm{hr}$, controls: $6.14 \pm 1.87 \mathrm{~km} / \mathrm{hr} ; \mathrm{p}=0.036$ ). Concussed and control participants did not differ on any other driving simulation outcomes.

All significant correlations for the concussed and control group are presented in Table 3. We observed several strong $(r>0.50)$ and significant correlations between neuropsychological assessments and driving performance among both the concussed and control group (Table 3). Most notably, we found 
that poorer performance on symbol digit modalities ( $r=-0.54)$, ROCF accuracy $(r=-0.53)$, and the CNS Vital Signs verbal memory $(r=-0.77)$ and motor speed $(r=-$ 0.54) domains were significantly correlated with committing more frequent lane excursions among the concussed group, but not the control group. Slower ROCF recall time was significantly correlated with total crashes $(r=0.72)$ among the concussed group, but not the control group. Concussed participants with worse performance on CNS Vital signs cognitive flexibility $(r=-0.60)$ and executive function $(r=-0.61)$ received more total tickets. Fewer correlations were found between neuropsychological variables and simulated driving performance in the control group (Table 3).

\section{Discussion}

Despite being considered asymptomatic, individuals who had sustained a concussion presented with poorer driving performance compared to nonconcussed matched controls. We also observed several correlations between driving performance and neuropsychological assessments among the concussed group that were not observed among the control groups, providing preliminary results that may help guide future research efforts aimed at developing a comprehensive driving evaluation for individuals with a concussion.

Asymptomatic participants with a concussion were less able to center the vehicle in the lane, especially when navigating curves, resulting in $32 \%$ (concussed: $10.9 \pm 4.5$, controls: $7.4 \pm 2.4$ ) more lane excursions. Further analysis revealed that individuals with a concussion more frequently crossed the road edge (right side), but not the center line. Excursions into the road shoulder are 
less likely to have safety consequences because no traffic is typically present on the road shoulder. Though the differences in lane excursions suggest that concussion affects driving performance, lane excursions alone do not seem to contribute significantly to the understanding of driving impairment and crash risk. ${ }^{27}$ However, lane position variance (SDLP) increments as a result of driving under the influence of drugs and alcohol studies show very strong associations with motor vehicle crashes. ${ }^{28}$ Lane position variance is also a sensitive measure of vehicle control to detect driving difficulties in patients with neurological conditions, including Parkinson's disease, ${ }^{29}$ traumatic brain injury, ${ }^{30}$ and multiple sclerosis $^{31}$. The difference in average SDLP values between the concussed and control groups ranged between $0.06 \mathrm{~m}$ for the smooth left curve and $0.19 \mathrm{~m}$ for the sharp left curve. These SDLP differences are very similar compared to those found in Parkinson disease (between $0.06 \mathrm{~m}$ and $0.13 \mathrm{~m})^{10}$, traumatic brain injury (between 0.20 and $0.25 \mathrm{~m})^{30}$, and multiple sclerosis $(0.52)^{31}$. These results suggest that drivers with asymptomatic concussion may (temporarily) exhibit similar driving difficulties when compared with other neurological conditions. However, direct comparison with other studies warrants caution since SDLP greatly depends on the type of simulator used, the speed, and design of the driving simulator scenarios.

Similarly, standard deviation of speed is an important measure of driving safety. ${ }^{32}$ Unlike our study, Neyens et al. did not find significant differences in standard deviation of speed between patients with mild traumatic brain injury and controls during a coin sorting task. ${ }^{33}$ Difficulties experienced with vehicle control 
emerged particularly while navigating left curves. Competent drivers take a left curve by slowing down while approaching the curve near the road edge, drive nearer to the midline of the lane during the middle stretch of the curve, and exit the curve closer to the road edge while gradually speeding up. ${ }^{34}$ The concussed group showed more variability in speed adaptation and tended to drive closer to the road edge when compared to the non-concussed group. Further research is needed to determine whether impairments in lateral and longitudinal vehicle control following concussion predispose individuals with a concussion to motor vehicle crashes. The results of this study raise two pertinent questions: 1) Do the observed impairments on simulated driving mean that driving should be restricted following concussion? 2) If so, how should readiness to return to driving be determined?

We found that driving impairments persist throughout the full duration of concussion symptom recovery. Recommendations regarding readiness to return to driving following concussion are greatly needed, particularly because most individuals with a concussion and medical providers underestimate the need to restrict driving. ${ }^{14}$ Only $29 \%$ of general practitioners and emergency departments routinely give advice about when a person should return to driving. ${ }^{35}$ Among those that did provide recommendations, most suggest waiting at least 24 hours and others leave the decision to return to driving up to the patient's discretion. ${ }^{35}$ Consensus statements regarding concussion do not address return to driving. ${ }^{6,36}$ Further investigation will be necessary to determine the time point at which individuals with a concussion should return to driving and what assessment 
comprise the best evaluation of fitness to drive in populations that sustain concussion.

The observed differences between groups suggest that concussed individual may have lingering subclinical neuropsychological and motor impairments that influence their driving performance at a time point when they are considered asymptomatic. A comprehensive driving evaluation is needed to ensure fitness to drive among individuals with a concussion, but evidence concerning methods used to determine fitness to drive following concussion is lacking. ${ }^{37}$ Our study provides preliminary guidance regarding which neuropsychological functions may best indicate continued driving impairment following concussion. Poorer attention, working memory, psychomotor speed, visuo-spatial ability, visuo-constructive skills, cognitive flexibility, executive function, verbal memory, and motor speed all associated with poorer measures of driving performance among the concussed group, but not the control group. Previous studies suggest that these measures are also sensitive to driving impairments in patient populations with other neurological conditions. ${ }^{38,39}$ The significant correlations between neuropsychological performances and driving performances in the concussed group and the lack of significant correlations in the control group may be partly explained by a greater heterogeneity (higher standard deviation in most of tests) in the concussed group than in the control group. These results provide a starting point to guide further research ultimately aimed at providing clinicians tools to guide driving recommendations based on neuropsychological performance. Neuropsychological measures, such as those 
identified in our current study, may help to identify those who need to undergo further on-road testing. On-road driving studies or naturalistic driving studies can also help to identify the problems individuals with concussion experience on the road. Many of the observed neuropsychological domains were those assessed using a computerized neuropsychological assessment commonly used for concussion assessment. Though computerized administrations of neuropsychological assessments have shortcomings, it is promising that a tool that is already widely used for concussion assessment may be useful for guiding recommendations for driving following concussion.

This study is not without limitations. We utilized a small sample size of 28 college-aged individuals. Sustaining a concussion may influence driving performance differently in other age groups. Though driving simulation has been validated as an effective means of evaluating driving abilities ${ }^{40}$, on-road driving performance may differ. Future studies should consider evaluating driving following concussion using on-road driving tests. We chose to assess driving performance within 48 hours following symptom resolution because this is the most likely time at which a concussed individual would return to driving, however, symptom resolution does not equate to full concussion recovery. Future studies are needed to track driving performance further out from symptom resolution. We also did not assess whether participants with a concussion were at greater risk of being involved in a motor vehicle crash.

\section{Conclusion}


Despite being asymptomatic, concussed participants exhibited poor vehicle control, especially when navigating curves. These results suggest that driving impairments may persist beyond when individuals with a concussion have returned to normal driving. A comprehensive driving evaluation is needed to ensure fitness to drive among individuals with a concussion and our study provides guidance regarding which neuropsychological functions may best indicate continued driving impairment following concussion. Further research with a larger sample size is needed to determine when it is safe to return to driving following concussion.

Acknowledgements: This study was funded by the Office of the Vice President of Research at the University of Georgia.

Author Disclosure Statement: No competing financial interests exist for any authors. 


\section{References}

1. Langlois J.A., Rutland-Brown W., Wald M.M. (2006). The epidemiology and impact of traumatic brain injury: a brief overview. J Head Trauma Rehabil 21(5):375-378.

2. Guskiewicz K.M., Ross S.E., Marshall S.W. (2001). Postural stability and neuropsychological deficits after concussion in collegiate athletes. $J$ Athl Train 36(3):263-273.

3. McCrea M., Guskiewicz K.M., Marshall S.W., Barr W., Randolph C., Cantu R.C., Onate J.A., Yang J., Kelly J.P. (2003). Acute effects and recovery time following concussion in collegiate football players: the NCAA Concussion Study. JAMA 290(19):2556-2563.

4. Schmidt J.D., Register-Mihalik J.K., Mihalik J.P., Kerr Z.Y., Guskiewicz K.M. (2012). Identifying Impairments after concussion: normative data versus individualized baselines. Med Sci Sports Exerc 44(9):1621-1628.

5. McCrea M., Barr W.B., Guskiewicz K., Randolph C., Marshall S.W., Cantu R., Onate J.A., Kelly J.P. (2005). Standard regression-based methods for measuring recovery after sport-related concussion. $J$ Int Neuropsychol Soc 11(1):58-69.

6. McCrory P., Meeuwisse W.H., Aubry M., Cantu R.C., Dvorak J., Echemendia R.J., Engebretsen L., Johnston K., Kutcher J.S., Raftery M., Sills A., Benson B.W., Davis G.A., Ellenbogen R., Guskiewicz K.M., Herring S.A., Iverson G.L., Jordan B.D., Kissick J., McCrea M., McIntosh A.S., Maddocks D., Makdissi M., Purcell L., Putukian M., Schneider K., 
Tator C.H., Turner M. (2013). Consensus statement on concussion in sport: the 4th International Conference on Concussion in Sport, Zurich, November 2012. J Athl Train 48(4):554-575.

7. Barrash J., Stillman A., Anderson S.W., Uc E.Y., Dawson J.D., Rizzo M. (2010). Prediction of driving ability with neuropsychological tests:

demographic adjustments diminish accuracy. J Int Neuropsychol Soc 16(4):679-686.

8. Reger M.A., Welsh R.K., Watson G.S., Cholerton B., Baker L.D., Craft S. (2004). The relationship between neuropsychological functioning and driving ability in dementia: a meta-analysis. Neuropsychology 18(1):85-93.

9. Grace J., Amick M.M., D'Abreu A., Festa E.K., Heindel W.C., Ott B.R. (2005). Neuropsychological deficits associated with driving performance in Parkinson's and Alzheimer's disease. J Int Neuropsychol Soc 11(6):766775.

10. Uc E.Y., Rizzo M., Johnson A.M., Dastrup E., Anderson S.W., Dawson J.D. (2009). Road safety in drivers with Parkinson disease. Neurology 73(24):2112-2119 .

11. Devos H., Vandenberghe W., Tant M., Akinwuntan A.E., De Weerdt W., Nieuwboer A., Uc E.Y. (2013). Driving and off-road impairments underlying failure on road testing in Parkinson's disease. Mov Disord 28(14):1949-1956. 
12. Devos H., Brijs T., Alders G., Wets G., Feys P. (2013). Driving performance in persons with mild to moderate symptoms of multiple sclerosis. Disability and rehabilitation 35(16):1387-1393.

13. Fisk G.D., Schneider J.J., Novack T.A. (1998). Driving following traumatic brain injury: prevalence, exposure, advice and evaluations. Brain Inj 12(8):683-695.

14. Preece M.H., Geffen G.M., Horswill M.S. (2013). Return-to-driving expectations following mild traumatic brain injury. Brain Inj 27(1):83-91.

15. Preece M.H., Horswill M.S., Geffen G.M. (2010). Driving after concussion: the acute effect of mild traumatic brain injury on drivers' hazard perception. Neuropsychology 24(4):493-503.

16. Schneider J.J., Gouvier W.D. (2005). Utility of the UFOV test with mild traumatic brain injury. Appl Neuropsychol 12(3):138-142.

17. Preece M.H.W., Horswill M.S., Ownsworth T. (2016). Do self-reported concussions have cumulative or enduring effects on drivers' anticipation of traffic hazards? Brain Inj 3:1-7.

18. Guskiewicz K.M., Marshall S.W., Bailes J., McCrea M., Cantu R.C., Randolph C., Jordan B.D. (2005). Association between recurrent concussion and late-life cognitive impairment in retired professional football players. Neurosurgery 57(4):719-726.

19. Register-Mihalik J.K., Guskiewicz K.M., Mihalik J.P., Schmidt J.D., Kerr Z.Y., McCrea M.A. (2013). Reliable change, sensitivity, and specificity of a 
multidimensional concussion assessment battery: implications for caution in clinical practice. J Head Trauma Rehabil 28(4):274-283.

20. Gunstad J., Suhr J.A. (2001). 'Expectation as etiology' versus 'the good old days': Postconcussion syndrome symptom reporting in athletes, headache sufferers, and depressed individuals. J Int Neuropsychol Soc 7(3):323-333.

21. Verster J.C., Roth T. (2014). Excursions out-of-lane versus standard deviation of lateral position as outcome measure of the on-the-road driving test. Hum Psychopharmacol 29(4):322-329.

22. Kennedy R.S., Lane N.E., Berbaum K.S., Lilienthal M.G. (1993). Simulator sickness questionnaire: an enhanced method for quantifying simulator sickness. Int J Aviat Psychol 3(3):203-220.

23. Krantz J.H. Mental Rotation Experiment. http://psych.hanover.edu/JavaTest/CLE/Cognition/Cognition/MentalRotation.html , 2014.

24. Gualtieri C.T., Johnson L.G. (2006). Reliability and validity of a computerized neurocognitive test battery, CNS Vital Signs. Arch Clin Neuropsych 21:623-643.

25. Dovoedo Y.H., Chakraborti S. (2015). Boxplot-based outlier detection for the location-scale family. Commun Statist Simula Computa 44(6):14921513.

26. Cohen J. (1992). A power primer. Psychol Bull 112(1):155-159. 
27. Verster J.C., Roth T. (2014). Excursions out-of-lane versus standard deviation of lateral position as outcome measure of the on-the-road driving test. Hum Psychopharmacol 29(4):322-329.

28. Owens K., Ramaekers J.G. Drugs, driving, and models to measure driving impairment. In: Verster JC, Pandi-Perumal SR, Ramaekers JG, de Gier JJ, eds. Drugs, Driving and Traffic Safety. Basel: Birkhäuser Basel; 2009:43-58

29. Uc E.Y., Rizzo M., Anderson S.W., Dastrup E., Sparks J.D., Dawson J.D. (2009). Driving under low-contrast visibility conditions in Parkinson disease. Neurology 73(14):1103-1110.

30. Brouwer W., Busscher R.B., Davidse R.J., Pot H., van Wolffelaar P.C. Traumatic brain injury: Tests in a driving simulator as part of the neuropsychological assessment of fitness to drive. In: Fisher DL, Rizzo M, Caird JK, Lee JD, eds. Handbook of Driving Simulation for Engineering, Medicine, and Psychology. Boca Raton, FL: CC Press; 2011.

31. Marcotte T.D., Rosenthal T.J., Roberts E., Lampinen S., Scott J.C., Allen R.W., Corey-Bloom J. (2008). The Contribution of Cognition and Spasticity to Driving Performance in Multiple Sclerosis. Archives of Physical Medicine \& Rehabilitation 89(9):1753-1758.

32. Reed M.P., Green P.A. (1999). Comparison of driving performance onroad and in a low-cost simulator using a concurrent telephone dialling task. Ergonomics 42(8):1015-1037. 
33. Neyens D.M., Boyle L.N., Schultheis M.T. (2015). The Effects of Driver Distraction for Individuals With Traumatic Brain Injuries. Hum Factors 57(8):1472-1488.

34. Stolwyk R.J., Triggs T.J., Charlton J.L., lansek R., Bradshaw J.L. (2005). Impact of internal versus external cueing on driving performance in people with Parkinson's disease. Mov Disord 20(7):846-857.

35. Moore C., Leathem J. (2004). Information provision after mild traumatic brain injury (MTBI): a survey of general practitioners and hospitals in New Zealand. N Z Med J 117(1201):U1046-U1046.

36. Broglio S.P., Cantu R.C., Gioia G.A., Guskiewicz K.M., Kutcher J., Palm M., Valovich McLeod T.C. (2014). National Athletic Trainers' Association Position Statement: Management of Sport Concussion. J Athl Train 49(2):245-265.

37. Baker A., Unsworth C.A., Lannin N.A. (2015). Determining fitness to drive: A systematic review of the methods and assessments used after mild traumatic brain injury. Br J Occup Ther 78(2):73-84 12p.

38. Dawson J.D., Uc E.Y., Anderson S.W., Johnson A.M., Rizzo M. (2010). Neuropsychological Predictors of Driving Errors in Older Adults. J Am Geriatr Soc 58(6):1090-1096.

39. Cullen N., Krakowski A., Taggart C. (2014). Early neuropsychological tests as correlates of return to driving after traumatic brain injury. Brain Inj 28(1):38 
40. Mayhew D.R., Simpson H.M., Wood K.M., Lonero L., Clinton K.M., Johnson A.G. (2011). On-road and simulated driving: concurrent and discriminant validation. J Safety Res 42(4):267-275. 
Table 1. Demographic and Driving Performance Results for Concussed and Matched Control Groups.

\begin{tabular}{rrrr}
\hline & $\begin{array}{c}\text { Concussed } \\
(\mathbf{n}=\mathbf{1 4})\end{array}$ & $\begin{array}{c}\text { Matched } \\
\text { Controls } \\
(\mathbf{n}=\mathbf{1 4})\end{array}$ & \\
\hline $\begin{array}{l}\text { Demographic } \\
\text { information }\end{array}$ & Mean \pm SD & Mean \pm SD & p value \\
\hline Age (yrs) & $20.2 \pm 0.9$ & $20.4 \pm 1.1$ & 0.607 \\
\hline Years of Education (yrs) & $12.9 \pm 1.1$ & $13.2 \pm 1.4$ & 0.544 \\
\hline Previous Concussions & $0.9 \pm 1.0$ & $0.3 \pm 0.8$ & 0.075 \\
\hline $\begin{array}{r}\text { Years of Driving } \\
\text { Experience }\end{array}$ & $4.4 \pm 1.0$ & $4.1 \pm 1.1$ & 0.545 \\
\hline $\begin{array}{r}\text { Previous Motor Vehicle } \\
\text { Crashes }\end{array}$ & $0.3 \pm 0.5$ & $0.3 \pm 0.6$ & 1.000 \\
\hline $\begin{array}{r}\text { Previous Driving } \\
\text { Violations }\end{array}$ & $0.3 \pm 0.6$ & $0.4 \pm 0.5$ & 0.737 \\
\hline Driving Performance & & $1.0 \pm 0.8$ & 0.262 \\
\hline Total Number of Crashes & $1.4 \pm 1.2$ & $9.0 \pm 4.5$ & 0.375 \\
\hline Total Number of Tickets & $10.8 \pm 5.9$ & $7.4 \pm 2.4$ & $0.017^{*}$ \\
\hline Total Number of Lane \\
Excursions & $10.9 \pm 4.5$ & & \\
\hline Signicant difference & & &
\end{tabular}

${ }^{*}$ Significant difference 
Table 2. Graded Symptom Checklist and Neuropsychological Assessment Results for Concussed and Matched Control Groups.

\begin{tabular}{|c|c|c|c|}
\hline & $\begin{array}{c}\text { Concussed } \\
(n=14)\end{array}$ & $\begin{array}{c}\text { Matched } \\
\text { Controls } \\
(n=14)\end{array}$ & \\
\hline & Mean \pm SD & Mean \pm SD & $\begin{array}{c}\text { p } \\
\text { value }\end{array}$ \\
\hline \multicolumn{4}{|l|}{ Graded Symptom Checklist } \\
\hline $\begin{array}{r}\text { Total Symptom Score (Now) (max } \\
\text { score: } 108)\end{array}$ & $4.6 \pm 4.5$ & $3.2 \pm 4.3$ & 0.423 \\
\hline $\begin{array}{r}\text { Total Symptom Score (Regular } \\
\text { Basis) (max score: 108) }\end{array}$ & $5.5 \pm 5.2$ & $3.4 \pm 4.8$ & 0.282 \\
\hline \multicolumn{4}{|l|}{ Neuropsychological Assessment } \\
\hline Trails Making Test A (s)* & $18.8 \pm 4.6$ & $16.9 \pm 4.8$ & 0.303 \\
\hline Trails Making Test B $(\mathrm{s})^{*}$ & $36.6 \pm 8.4$ & $43.0 \pm 19.4$ & 0.267 \\
\hline Symbol Digit Modalities Test & $64.1 \pm 10.0$ & $67.6 \pm 7.0$ & 0.293 \\
\hline $\begin{array}{r}\text { ROCF Copy Score (max score: } \\
36 \text { ) }\end{array}$ & $33.3 \pm 2.7$ & $33.8 \pm 2.1$ & 0.614 \\
\hline ROCF Copy Time $(\mathrm{s})^{*}$ & $133.8 \pm 41.6$ & $112.5 \pm 25.5$ & 0.135 \\
\hline $\begin{array}{r}\text { ROCF Recall Score (max score: } \\
36 \text { ) }\end{array}$ & $23.6 \pm 4.9$ & $22.3 \pm 4.5$ & 0.476 \\
\hline ROCF Recall Time $(\mathrm{s})^{*}$ & $132.2 \pm 98.3$ & $110.7 \pm 22.0$ & 0.450 \\
\hline $\begin{array}{r}\text { Mental Rotation Score (max } \\
\text { score: } 70)\end{array}$ & $59.3 \pm 9.6$ & $53.5 \pm 12.6$ & 0.188 \\
\hline $\begin{array}{r}\text { Mental Rotation Reaction Time } \\
(\mathrm{ms})^{*}\end{array}$ & $4317.3 \pm 2073.1$ & $3175.7 \pm 1888.1$ & 0.148 \\
\hline \multicolumn{4}{|l|}{ CNS Vital Signs Raw Scores(unitless) } \\
\hline Verbal Memory & $53.2 \pm 5.3$ & $54.8 \pm 4.9$ & 0.467 \\
\hline Visual Memory & $47.2 \pm 6.0$ & $49.9 \pm 5.0$ & 0.225 \\
\hline Psychomotor Speed & $194.3 \pm 28.8$ & $188.2 \pm 19.1$ & 0.540 \\
\hline Reaction Time* & $647.9 \pm 103.8$ & $590.2 \pm 52.1$ & 0.096 \\
\hline Complex Attention* & $11.3 \pm 10.7$ & $6.3 \pm 3.6$ & 0.138 \\
\hline Cognitive Flexibility & $46.1 \pm 16.1$ & $51.5 \pm 7.5$ & 0.298 \\
\hline Processing Speed & $73.1 \pm 15.3$ & $75.6 \pm 13.0$ & 0.664 \\
\hline Executive Function & $47.9 \pm 14.7$ & $52.5 \pm 6.9$ & 0.336 \\
\hline Simple Attention & $37.3 \pm 4.9$ & $39.1 \pm 1.0$ & 0.232 \\
\hline Motor Speed & $118.4 \pm 17.6$ & $111.0 \pm 10.7$ & 0.222 \\
\hline
\end{tabular}

${ }^{*}$ Lower score indicates better performance ROCF: Rey Osterrieth Complex Figure 
Table 3. Significant Correlations between Neuropsychological Assessment and Driving Performance.

\begin{tabular}{|c|c|c|c|c|}
\hline & \multicolumn{2}{|c|}{ Concussed } & \multicolumn{2}{|c|}{ Controls } \\
\hline & $\begin{array}{c}\text { Neuropsychological } \\
\text { Assessment }\end{array}$ & $\begin{array}{c}\mathbf{R} \text { value } \\
\text { (interpretation) }\end{array}$ & $\begin{array}{c}\text { Neuropsychological } \\
\text { Assessment }\end{array}$ & $\begin{array}{c}\mathbf{R} \text { value } \\
\text { (interpretation) }\end{array}$ \\
\hline $\begin{array}{l}\text { Total } \\
\text { crashes }^{*}\end{array}$ & ROCF Recall Time* & $0.72(+)$ & Visual Memory & $-070(+)$ \\
\hline $\begin{array}{l}\text { Total } \\
\text { tickets* }\end{array}$ & $\begin{array}{l}\text { Cognitive Flexibility } \\
\text { Executive Function }\end{array}$ & $\begin{array}{l}-0.60(+) \\
-0.61(+)\end{array}$ & $\begin{array}{l}\text { ROCF Recall Time* } \\
\text { Reaction Time }\end{array}$ & $\begin{array}{l}-0.71(-) \\
0.73(+)\end{array}$ \\
\hline $\begin{array}{l}\text { Total } \\
\text { weaving* }\end{array}$ & Verbal memory & $-0.77(+)$ & N.S. & \\
\hline $\begin{array}{l}\text { Road edge } \\
\text { excursions }\end{array}$ & $\begin{array}{r}\text { SDMT } \\
\text { Verbal memory } \\
\text { Motor Speed }\end{array}$ & $\begin{array}{l}-0.54(+) \\
-0.76(+) \\
-0.54(+)\end{array}$ & N.S. & \\
\hline $\begin{array}{l}\text { Centerline } \\
\text { crossing }^{*}\end{array}$ & ROCF Copy Score & $-0.53(+)$ & N.S. & \\
\hline $\begin{array}{l}{ }^{*} \text { Indicates that } \\
\text { SDMT: Symbo } \\
\text { ROCF: Rey Os } \\
\text { MR: Mental Ro } \\
\text { N.S.: not signi } \\
\text { (+)When test } p \\
\text { (-)When test pe }\end{array}$ & $\begin{array}{l}\text { a higher values represe } \\
\text { I Digit Modalities Test } \\
\text { sterrieth Complex Figu } \\
\text { otation } \\
\text { ificant } \\
\text { berformance decreased, } \\
\text { erformance decreased, }\end{array}$ & ts poorer perfor & $\begin{array}{l}\text { declined. } \\
\text { mproved. }\end{array}$ & \\
\hline
\end{tabular}

